\title{
Transforming Leaders Into Stewards Of Teaching Excellence: Building And Sustaining An Academic Culture Through Leadership Immersion
}

\author{
Candice Phillips, Chamberlain College of Nursing, USA \\ Kellie Bassell, Chamberlain College of Nursing, USA \\ Laura Fillmore, Chamberlain College of Nursing, USA \\ Winsome Stephenson, Chamberlain College of Nursing, USA
}

\begin{abstract}
Nursing must transform education and practice to meet the changing healthcare environment; yet, steps to desired change remain unknown. Academic leaders are well-positioned to initiate change and transform the academic landscape. However, many advance to leadership positions with minimal orientation to the role. Moreover, leaders in academic nursing often have expertise as clinicians and administrators, and not as academics. It is incumbent on nurse leaders to acquire needed competencies to fulfill the academic role. The purpose of this quality improvement project was to immerse leaders in an exploration of steps to initiate and sustain change in the teaching and learning process. Self-reported low-and high-level outcomes were analyzed using Kirkpatrick's Model (1994) to evaluate the effectiveness of the immersion in preparing leaders to build and sustain a quality academic culture. Leadership immersions were implemented to transform leaders into stewards of teaching excellence. Pre-and post-immersion surveys captured data across three levels: satisfaction, knowledge and skill acquisition, and change in behavior. Seventy-three participants were evaluated. Participants for inclusion in the three-month analysis culminated in a $41 \%$ response rate. Findings were analyzed using ANOVA and t-tests. Further analysis was performed using Cohen's $d$ to determine effect size. Three-month follow-up surveys revealed no significant effect change $(p<0.05)$. Results suggest immersion is effective in preparing leaders of academic nursing to build a quality academic culture. Through immersion, leaders established a collective vision of teaching excellence and proficiency in confronting and resolving actual and desired teaching practices, while enriching the life and work of faculty.
\end{abstract}

Keywords: Leadership Development; Immersion; Academic Culture; Nursing

\section{INTRODUCTION}

n 2010, landmark reports from the Carnegie Foundation for the Advancement of Teaching (Benner, Sutphen, Leonard, \& Day, 2010) and the IOM task force on the Future of Nursing charged nurse educators with effectively preparing nurses to practice in the rapidly changing health care environment. In 2015 ,
the IOM (now known as the National Academy of Medicine) assessed progress made on implementing The Future of Nursing report recommendations. Findings revealed continuing need for nursing education to meet the demands of the increasingly complex health care environment. Although nursing is called to transform education and practice, proven process steps leading to desired change remain unknown (Sherwood \& Horton-Deutsch, 2014). Additionally, the complexity of today's education system, with the many internal and external influences that act upon it, make implementation of improvements difficult to sustain. Therefore, many nursing programs seek an efficient and effective method for building and sustaining a quality academic culture for teaching nursing.

Academic leaders, equipped with the knowledge, skills, and attitudes to build quality academic cultures, are wellplaced to initiate change and transform the current academic landscape. However, leaders often advance to academic leadership positions with limited orientation to the role and must acquire needed competencies foundational to the 
fulfillment of the academic leadership role (Söderhjelm, Björklund, Sandahl, \& Bolander-Laksov, 2016). The purpose of this quality improvement project was twofold:

- first, to develop and implement regional, strategic leadership immersions to guide academic leaders in an in-depth exploration of steps to initiate and sustain change in the teaching and learning process across our multistate, prelicensure nursing program; and,

- $\quad$ second, to use Kirkpatrick's 4-Level Model (1994) to analyze self-reported low- and high-level outcomes of the leadership immersions to effectively prepare leaders to build and sustain a quality academic culture at their campus locations.

To this end, our faculty development team developed and implemented regional, strategic leadership immersions to transform leaders of academic nursing into stewards of teaching excellence.

\section{BACKGROUND}

Change is difficult to implement and sustain in an organizational system. Therefore, an important first step in achieving educational transformation is to create an infrastructure to support change (Sabelli \& Dede, 2013). Joining faculty, leaders, and faculty developers in a collaborative vision with the strategic direction of the institution is vital to building an intentional academic culture (Neal \&Peed-Neal, 2010). This intraprofessional collaboration creates a shared responsibility for prioritizing, cultivating, and sustaining teaching excellence through integration of new competencies and advances in education (Sherwood \& Horton-Deutsch, 2014). Emphasis on faculty development is especially important to advance scholarly competence and facilitate socialization and role development of academics (Sarikaya, Kalaca, Yegen, \& Cali, 2010).

Fundamental to the role of any academic leader is to coach the faculty they lead (Day, Fleenor, Atwater, Sturm, \& McKee, 2014). Indeed, academic leaders are called to continually inspire and guide faculty to reach their full potential. However, leaders often advance to academic leadership positions without receiving effective orientation to their role (Söderhjelm, et al. 2016). Moreover, leaders in academic nursing often possess expertise as clinicians and organizational administrators, and not as nurse academics (Halcomb, et al., 2015). Therefore, it is incumbent on leaders in academic nursing to acquire needed competencies foundational to fulfillment of the academic role. Nursing leadership role competencies specific to education require a specialized pedagogical base that integrates the art and science of nursing practice with the teaching and learning process.

Therefore, another step in building an intentional educational culture is strategic development for leaders of academic nursing. Through leadership development, internalizing beliefs, values, and attitudes toward academic nursing is championed, promoting formation of leaders as excellent nurse academics (Cannaby, Libacao, Hassanein, \& Gray, 2016). Engaging academic leaders in knowledge and resource sharing enhances awareness and understanding of effective teaching practice, equipping them to support faculty teaching and development and lead the academic team. Additionally, leadership development identifies and models responsibilities among and between the various academic leadership roles, particularly, how these roles complement, and are accountable and relate to, one another (Paradeise $\&$ Thoenig, 2013). A shared identity can be forged among leaders, including a shared perception of quality outcomes and commitment to act collectively in advancing standards of excellence in teaching. Collective action by wellequipped leaders supports the transformation of the academic culture into an environment that enhances scholarly activities and teaching productivity (Staffileno, Murphy, \& Carlson, 2016). Promoting an intentional culture of teaching excellence can lead to a positive and sustained impact on individual and collective teaching practices, and on successful student outcomes (Halstead, 2009; Paradeise \& Thoenig, 2013).

Moreover, strategic leadership development enhances the capacity of nurse academic leaders to serve as stewards of teaching excellence. Through leadership development, academic leaders are empowered to guide the direction and vision of excellence for faculty. As stewards, leaders support faculty to embrace and embody this vision, transforming the organization into an intentional educational culture of academic quality. 


\section{INTENDED IMPROVEMENT: EMPOWER ACADEMIC LEADERS TO BUILD AND SUSTAIN A QUALITY ACADEMIC CULTURE THROUGH LEADERSHIP IMMERSION}

In response to calls for academic reform in nursing education, three regional leadership immersions were designed and implemented by our Center for Faculty Excellence (CFE) to prepare leaders to build and sustain a quality academic culture across our multistate, prelicensure nursing program. Academic leaders, including campus presidents, deans of academic affairs, and associate deans of faculty were required to attend one of three regional, immersive events that were offered within a seven-week period. Leadership teams from each location were encouraged but not required to attend together. Prior to arrival, participants were required to complete a faculty development curriculum developed by the CFE. This structured development plan builds competencies needed for effective teaching for both beginning and seasoned nurse educators through innovative eLearning courses and resources. Foundational to these resources are learning activities regarding the effective use of evidence-based pedagogies to facilitate student achievement of course and program outcomes.

The focused three-day immersion agenda was developed to support and guide academic leaders to reflect upon and effectively use the structured faculty development program to support faculty teaching and development at their campus location. Integral to the immersive experience was the opportunity for leaders to challenge perceptions and gather insights about influences on their role as leaders of academic nursing. The goal was for participants to learn about themselves as leaders, develop expertise in guiding faculty to link how teaching practice connects with student learning, and use the information and resources gathered to improve teaching practice at their location. Additionally, the immersion provided opportunity for participants to create and deepen collaborative connections with other leaders of academic nursing from across the College. Activities throughout the immersion were facilitated by CFE members.

Day one of the leadership immersion established the foundation for building a quality academic culture. Emphasis was placed on how this strategic initiative fulfills the College mission to transform healthcare. Leaders reflected upon attributes -knowledge, skills, and attitudes - that exemplify teaching excellence. They also identified and shared the responsibilities of academic leadership in which they excel, as well as the strengths they bring to building a quality academic culture. A collective process of reflection was used to generate shared meanings and enhance networking (Sherwood \& Horton-Deutsch, 2014). Importantly, connections were forged between developing and seasoned leaders for future leadership coaching. Through individual and collective reflection, a shared vision of teaching excellence was identified, including how various academic leadership roles contribute to and are accountable for advancing teaching excellence.

Also on day one the structured faculty development program was overviewed, with emphasis placed on how these resources can be used to personalize learning for faculty, taking into account their experience, knowledge, and learning goals. Leaders explored how these resources can be used with individual faculty members to guide professional development and/or performance remediation. They also considered how these resources can be used with faculty teams to enhance knowledge by generating purposeful, collaborative dialog and reflection. Day one of the immersion concluded with small group teach-back demonstration to engage leaders in using these resources in addressing commonly encountered issues related to faculty teaching and development. The teach-back method assures effective leader-to-faculty communication through experiential learning and constructive feedback (McPeck, 2016). Following the teach-back presentations, leaders reflected, individually and collectively, upon the barriers and facilitators associated with building a quality academic culture.

Day two of the leadership immersion engrossed leaders in providing effective feedback to guide faculty development at their campus location. An animated, interactive eLearning video was used to model effective leadership guidance to a faculty member ineffectively using an instructional method during a classroom observation. Performance-based decisions put the learner in a situation to use information and apply skills to the nuances of real-life decisions, demonstrating greater levels of understanding (Rahmani, Mohammadi, \& Moradi, 2016). Following the video, small group teach-back demonstration was again used to engage leaders in the collaborative use of faculty development resources to respond to case scenarios about faculty teaching and development. Following the presentations, leaders reflected upon what they know, believe, and value within the context of the case scenarios to guide future responses and actions in the leadership role. Day two of the leadership immersion culminated in collaboration among leaders to create a strategic faculty development plan to implement at their location. 
Day three of the leadership immersion engaged leaders in dialog about processes to support ongoing faculty academic development at their campus location. Reflection activities invited leaders to identify and share personal and professional values that were challenged by the leadership immersion, and how their understanding of their role changed over the course of the event, if at all. Day three of the leadership immersion closed with leaders pledging their commitment to advancing teaching excellence. To honor their commitment and dedication, leaders were awarded with College lapel pins and email badges signifying their dedication to teaching excellence.

\section{THEORETICAL FRAMEWORK: \\ LEADERSHIP IMMERSION EVALUATION USING KIRKPATRICK'S 4-LEVEL MODEL}

To measure outcomes of the leadership immersion, a strategic evaluation plan was developed using Kirkpatrick's 4Level Model (1994). Kirkpatrick's Model (1994) is commonly used to determine the effectiveness of professional development initiatives across the field of health professions education (Leslie, Baker, Egan-Lee, Esdalie, \& Reeves, 2013; Opperman, Liebig, Bowling, Johnson, \& Harper, 2016; Zheng, Bender, \& Nadershahi, 2015). This hierarchy model uses four levels of criteria to evaluate outcomes of professional development, including: learner satisfaction, knowledge and skill acquisition, application of new knowledge and skills, and the achievement of mission-critical goals. The use of four levels of evaluation ensure professional development offerings demonstrate transfer of learning to behavior change in participants. Importantly, data demonstrating effectiveness of professional development resources in contributing to key organizational outcomes allows faculty developers to credibly show the value they bring to the institution.

Commonly, only low-level outcomes targeting learner satisfaction are reported across health professions education (Dreyer et al. 2015; Haji, Morin, \& Parker, 2013; Lapkin, Levett-Jones, \& Gilligan, 2015). Learner satisfaction is important; however, higher-level outcomes focus on transfer of learning to behavior change in participants. This higher-level data provides insight into the effectiveness of professional development resources to transform professional practice. Therefore, we evaluated levels 1, 2, and 3 outcomes based on Kirkpatrick's Model (1994), including

1. satisfaction with the leadership immersion, including content, delivery methods, and structure;

2. leader knowledge and skill acquisition, including self-reported improvement in understanding of content presented, ability to integrate the content into the academic leadership role, and value of the content presented; and

3. direct application of newly acquired strategies to build and sustain a quality academic culture.

\section{METHODOLOGY}

\section{Context}

Our nursing program is a large multistate, multiprogram, non-tenure institution in the United States. The Bachelor of Science in Nursing (BSN) degree program is available at 20 campuses across 14 states. Each campus employs a cadre of diverse academic leaders and full- and part-time faculty. Campus leadership includes the campus president, dean of academic affairs, associate dean of academic operations, and associate dean(s) of faculty. Faculty numbers vary at each location determined by student enrollment. The CFE is a decentralized, national team consisting of the dean of faculty, four faculty development specialists, a senior instructional designer, and web designer, who provide comprehensive eLearning resources to guide and support the development of beginning and experienced nurse educators in the academic role. Given the span of our prelicensure nursing program across 20 campuses, leaders are integral in guiding faculty teaching and development through implementation of CFE courses and resources at their location. 


\section{Planning}

Three regional leadership immersions were offered to guide leaders to reflect upon the academic leadership role and effectively use a structured faculty development program to support faculty teaching and development. Over the course of three days, academic leaders were led on a transformative journey to challenge assumptions and raise questions about the academic leadership role; namely, about the responsibilities and accountabilities of leaders in academic nursing to build a quality academic culture for teaching nursing. This focus on leaders learning about learning was an intentional move from traditional training toward evidence-based professional development that places value and importance on reflection to enhance transfer of learning to the workplace (Steinert, 2014). Moreover, reflection is foundational to transformative learning and facilitates new and novel ways of thinking (Santalucia \& Johnson, 2010). Integral to this immersion was the opportunity for academic leaders to reflect upon the knowledge, skills, and attitudes required to build a quality academic culture and the importance of transmitting that culture to faculty. Equally important was allowing time for academic leaders to rethink assumptions that may have hindered them from embracing the change necessary to support and guide faculty performance. Therefore, an immersive agenda including individual and collective dialogic reflection and performance-based eLearning interactives was developed to invite leaders to practice new skills in a compelling way.

Engaging eLearning interactives were used to transform static leadership training into ongoing, active, performancebased learning. These eLearning interactives for professional development provide efficient and cost-effective delivery, as well as a flexible, asynchronous framework for self-guided learning. Situations and concepts that connect leaders with day-to-day role responsibilities were depicted, putting learners in the position of discovering new information for themselves and applying it to real-life decisions to demonstrate understanding. Animated, virtual coaches provide relevant, content-rich feedback during decision-making, offering explanations or additional challenges to deepen learning. eLearning activities can be completed multiple times to test knowledge development; moreover, their online format allows leaders to return to them when confronted by a similar scenario at their campus location.

\section{Design and Methods of Evaluation}

This quality improvement project employed a mixed-methods design to examine the processes and outcomes of immersive leadership development to prepare leaders in academic nursing to build an intentional educational culture of academic quality at their prelicensure campus. Kirkpatrick's Model (1994) was utilized to evaluate pre- and postimmersion survey data across three identified levels: faculty satisfaction, faculty knowledge and skill acquisition, and a change in leadership behavior, namely, to what degree the academic leader applies what was learned at three months after the immersion.

Data was collected using a 5-item Likert-like Scale, with responses ranging from 1 (strongly disagree) to 5 (strongly agree). Pre-immersion surveys were administered at the start of day one of the immersion. This survey addressed leader ratings of their knowledge, skills, and attitudes toward the faculty development program to support faculty teaching and development. This pre-immersion survey aligns with level 1 of Kirkpatrick's Model (1994). The postimmersion survey was administered on day three of the immersion and addressed these same areas of knowledge, skills, and attitudes toward the structured faculty development program. Additionally, the post-immersion survey addressed leader ratings of reaction (satisfaction, engagement, and relevancy of immersion content), and aspects of learning (confidence and commitment to the immersion content), which align respectively with levels 1 and 2 of the Kirkpatrick Model (1994).

Electronic post-immersion surveys were administered three months after completion of the leadership immersion to analyze a transfer of learning, namely, to what degree the leader applies information learned during the immersion in their leadership role at three months after the event. This three-month post-immersion survey aligns with level 3 of Kirkpatrick's Model (1994). 


\section{Analysis and Findings}

The sample size was 73 participants. This sample represented the number of academic leaders from across 20 prelicensure campus locations who attended one of the three leadership immersions. At the time of data analysis, 73 participants were eligible to be evaluated for levels 1 and 2 of Kirkpatrick's Model (1994), based on the completion of pre- and post-immersion surveys. Of the 73 participants eligible for inclusion in the three-month analysis, 30 participants responded culminating in a $41 \%$ response rate.

An analysis of the study sample was conducted using descriptive and inferential statistics. Descriptive statistics for all three surveys (pre-immersion, post-immersion, and three-month follow-up) are presented in Table 1.

Table 1. Longitudinal Descriptive Statistics for Knowledge, Skills, and Attitude

\begin{tabular}{|c|c|c|c|c|c|c|c|c|c|}
\hline & \multicolumn{3}{|c|}{ Pre-immersion Survey } & \multicolumn{3}{|c|}{ Post-immersion Survey } & \multicolumn{3}{|c|}{$\begin{array}{c}\text { Three Month Follow-up } \\
\text { Survey }\end{array}$} \\
\hline & M & SD & $\mathbf{N}$ & M & SD & $\mathbf{N}$ & M & SD & $\mathbf{N}$ \\
\hline \multicolumn{10}{|l|}{ Chicago } \\
\hline Knowledge & 3.95 & 0.78 & 22 & 4.64 & 0.49 & 22 & 4.50 & 0.53 & 10 \\
\hline Skills & 3.73 & 0.77 & 22 & 4.50 & 0.60 & 22 & 4.20 & 0.63 & 10 \\
\hline Attitude & 4.64 & 0.73 & 22 & 4.95 & 0.21 & 22 & 4.90 & 0.32 & 10 \\
\hline \multicolumn{10}{|l|}{ Atlanta } \\
\hline Knowledge & 4.00 & 0.71 & 17 & 4.88 & 0.33 & 17 & 4.50 & 0.58 & 4 \\
\hline Skills & 3.82 & 0.81 & 17 & 4.82 & 0.39 & 17 & 4.50 & 0.58 & 4 \\
\hline Attitude & 4.94 & 0.24 & 17 & 4.94 & 0.24 & 17 & 5.00 & 0.00 & 4 \\
\hline \multicolumn{10}{|l|}{ Phoenix } \\
\hline Knowledge & 3.91 & 0.83 & 34 & 4.68 & 0.47 & 34 & 4.56 & 0.51 & 16 \\
\hline Skills & 3.76 & 0.82 & 34 & 4.44 & 0.50 & 34 & 4.56 & 0.51 & 16 \\
\hline Attitude & 4.94 & 0.24 & 34 & 4.97 & 0.17 & 34 & 4.69 & 0.48 & 16 \\
\hline
\end{tabular}

Note: $\mathrm{M}=$ mean. $\mathrm{SD}=$ standard deviation. $\mathrm{N}=$ sample size.

Analysis of the pre-immersion group data for knowledge was conducted using a one-way between-subjects ANOVA, where group location served as the factor and score served as the outcome variable. Using an alpha level of .05, the effect of the location of knowledge on the pre-immersion survey was not significant, $F(2,70)=3.128, p=.930$. Using an alpha level of .05 , the effect of the location of knowledge on the post-immersion survey was not significant, $\mathrm{F}(2$, $70)=3.128, \mathrm{p}=.205$.

Analysis of the pre-immersion group data for skills was performed using a one-way between-subjects ANOVA, where group location served as the factor and score served as the outcome variable. Using an alpha level of .05, the effect of the location for skills on the pre-immersion survey was not significant, $F(2,70)=3.128, p=.933$. Using an alpha level of .05 , the effect of the location for skills on the post-immersion survey was significant, $\mathrm{F}(2,70)=3.128, \mathrm{p}=$ .043. Results indicate there was a significant difference between at least one of the location groups. Using the Bonferroni correction to adjust for multiple comparisons at a 95\% confidence level there is a significant difference between groups two (Atlanta) and three (Phoenix). This difference may be attributed to the fewer number of participants at the Atlanta location. Fewer participants resulted in smaller group size and increased the opportunity to interact with the eLearning interactives which may have accounted for a higher self-rating of skill ability.

Analysis of the pre-immersion group data for attitudes was completed using a one-way between-subjects ANOVA, where group location served as the factor and score served as the outcome variable. Using an alpha level of .05, the effect of the location of attitude on the pre-immersion survey was significant, $F(2,70)=3.128, p=.032$. Results indicate there was a significant difference between at least one of the location groups. Using the Bonferroni correction to adjust for multiple comparisons at a $95 \%$ confidence level there is a significant difference between group one (Chicago) and groups two (Atlanta) and three (Phoenix). Using an alpha level of .05, the effect of the location of attitudes on the post-immersion survey was not significant, $F(2,70)=3.128, p=.880$. This pre-immersion difference may represent a threat to internal validity, as the length of time between group 1 and groups 2 and 3 (four and six weeks, respectively) resulted in discussion at the College of the leadership immersion between those who had attended and those who had not yet attended an immersion. 
Additional inferential statistics included the use of t-tests and Cohen's d. The level of significance for the study was 0.05 . The pre- and post-immersion survey scores were analyzed using a one-tailed, dependent t-test. The knowledge effect was statistically significant, $\mathrm{t}(72)=-7.363$, and $\mathrm{p}=1.17 \mathrm{E}-10$, at an alpha level of 0.05 . The skill effect also was statistically significantly, $\mathrm{t}(72)=-7.813$, and $\mathrm{p}=1.71 \mathrm{E}-111$, at an alpha level of 0.05 . Likewise, the attitude effect was statistically significant, $\mathrm{t}(72)=-2.193$, and $\mathrm{p}=0.0158$, at an alpha level of 0.05 .

Descriptive statistical analysis was performed using a Cohen's $d$ to determine the effect size of participation in the leadership immersion on participants' knowledge, skills, and attitudes. Regarding knowledge, Cohen's $\mathrm{d}=1.21$, which indicated a large impact for participation in the leadership immersion on the post-immersion survey scores. Regarding skill, Cohen's $d=1.16$, which indicated a large impact for participation in the leadership immersion on the post-test scores. Finally, regarding attitude, Cohen's $d=0.39$ which indicated a medium or moderate impact of participation in the leadership immersion on the post-immersion scores (Fritz, Morris \& Richler, 2012).

Post-immersion survey results were also analyzed utilizing inferential and descriptive statistics for the six items delineated in Table 2. All six items were analyzed using a one-way between-subjects ANOVA, where group location served as the factor and score served as the outcome variable. Using an alpha level of .05, the effect of the location for all six items was not significant except for relevancy. Results indicated there was a significant difference between at least one of the location groups for relevancy. Using the Bonferroni correction to adjust for multiple comparisons at a $95 \%$ confidence level there is a significant difference between group two (Atlanta) and group three (Phoenix).

Table 2. Descriptive Statistics for combined post-immersion survey items aligned with Kirkpatrick's Levels of Evaluation

\begin{tabular}{l|l|l|l|l|}
\hline Kirkpatrick Level of Evaluation & Post-immersion Survey Item & M & SD & N \\
\hline \multirow{4}{*}{ Level 1 - Reaction } & Satisfaction & 4.78 & 0.42 & 73 \\
& Expectations & 4.64 & 0.51 & 73 \\
\hline & Relevancy & 4.90 & 0.29 & 73 \\
\hline \multirow{2}{*}{ Level 2 - Learning } & Engagement & 4.67 & 0.50 & 73 \\
\hline & Confidence & 4.69 & 0.49 & 73 \\
\cline { 2 - 6 } & Commitment & 4.90 & 0.30 & 73 \\
\hline
\end{tabular}

Note: $\mathrm{M}=$ mean. $\mathrm{SD}=$ standard deviation. $\mathrm{N}=$ sample size

Follow-up surveys employed three months after completion of the leadership immersion were analyzed to determine whether a change in knowledge, skills, and attitudes were sustained. Descriptive (see Table 1) and inferential analyses of the study sample were conducted comparing these results to the post-immersion surveys. Inferential statistics used included ANOVA and t-tests. Follow-up survey scores were analyzed to evaluate overall changes in post- immersion and three month follow-up surveys. Using a one-tailed, dependent t-test the knowledge effect was not statistically significant, $\mathrm{t}(29)=-0.29$, and $\mathrm{p}=0.38$, at an alpha level of 0.05 . Also, the skill effect was not statistically significantly, $\mathrm{t}(29)=0.27$, and $\mathrm{p}=0.39$, at an alpha level of 0.05 . Additionally, the attitude effect was also not statistically significant, $\mathrm{t}(29)=0.62$, and $\mathrm{p}=0.27$, at an alpha level of 0.05 . Furthermore, the three-month follow-up survey scores were analyzed using a single factor ANOVA to evaluate for any between-group differences see Tables 2 , $3 \&$ 4). No significant difference between groups for knowledge, skills, or attitude were noted.

Table 2. Analysis of Variance for Knowledge 3 Month follow-up

\begin{tabular}{l|c|c|c|c|c|c|}
\hline \multicolumn{1}{c}{ Source of Variation } & SS & $\boldsymbol{d f}$ & $\boldsymbol{M S}$ & $\boldsymbol{F}$ & $\boldsymbol{P}$-value & $\boldsymbol{F}$ crit \\
\hline Between Groups & 0.029167 & 2 & 0.014583 & 0.052941 & 0.948534 & 3.354131 \\
\hline Within Groups & 7.4375 & 27 & 0.275463 & & & \\
\hline Total & 7.466667 & 29 & & & & \\
\hline
\end{tabular}


Table 3. Analysis of Variance for Skills 3 Month follow-up

\begin{tabular}{|l|l|l|l|l|c|c|}
\hline \multicolumn{1}{|c|}{ Source of Variation } & \multicolumn{9}{|c|}{ ANOVA } & $\boldsymbol{F}$ & $\boldsymbol{P}$-value & $\boldsymbol{F}$ crit \\
\hline Between Groups & 0.829167 & 2 & 0.414583 & 1.311127 & 0.286132 & 3.354131 \\
\hline Within Groups & 8.5375 & 27 & 0.316204 & & & \\
\hline Total & 9.366667 & 29 & & & & \\
\hline
\end{tabular}

Table 4. Analysis of Variance for Attitudes 3 Month follow-up

\begin{tabular}{|c|c|c|c|c|c|c|}
\hline \multicolumn{7}{|c|}{ ANOVA } \\
\hline Source of Variation & $S S$ & $d f$ & $M S$ & $\boldsymbol{F}$ & P-value & F crit \\
\hline Between Groups & 0.4625 & 2 & 0.23125 & 1.439481 & 0.254669 & 3.354131 \\
\hline Within Groups & 4.3375 & 27 & 0.160648 & & & \\
\hline Total & 4.8 & 29 & & & & \\
\hline
\end{tabular}

\section{DISCUSSION}

To meet the twofold aim of this quality improvement project three regional leadership immersions were implemented to guide leaders of academic nursing to build and sustain a quality academic culture across 20 prelicensure campuses in our nursing program. During the three-day immersion, leaders reflected upon the academic leadership role, the attributes that exemplify teaching excellence, and how various leadership roles contribute to and are accountable for advancing teaching excellence. Additionally, leaders actively explored a structured faculty development program to support faculty teaching, as well as case scenarios to guide future responses and actions in the leadership role. The leadership immersion also provided an opportunity for leaders to create a strategic faculty development plan to implement at their location to support and enrich the life and work of faculty.

Findings suggest that the leadership immersion had a positive impact on outcomes corresponding to Kirkpatrick's 4Level Model (1994) of evaluation of professional development effectiveness. Faculty participants reported satisfaction with the leadership immersion (level 1 outcomes), improved knowledge and skill acquisition (level 2 outcomes), and direct application of newly acquired leadership capacity at three months following completion of the leadership immersion (level 3 outcomes). Results from the implementation of these immersive events suggest that leadership immersion is effective for leaders to build and sustain a quality academic culture. Data revealed that leadership immersion is effective for leaders to establish a collective vision of teaching excellence and increase proficiency in confronting and resolving actual and desired teaching practices at their campus location, while nurturing faculty growth and development in teaching nursing. Additionally, leaders reported high commitment to use the structured faculty development program to steward teaching excellence at their location, build an intentional academic culture, and advance student learning outcomes.

Preliminary findings from the leadership immersion support previous research findings that structured, well-designed leadership development that focuses on knowledge-sharing benefits leaders, their teams, and the organization alike (Branson, Franken, \& Penney, 2016). This quality improvement project contributes to the literature in nursing, the health sciences, and in higher education more broadly regarding the capacity for academic leaders to lead organizational change in transforming academic cultures through intensive leadership immersion. Additionally, this project guides educational organizations seeking leadership development programs by offering a structured immersion agenda.

Limitations in the quality improvement project may impact findings. Although the initial sample size was 73 participants, at the time of data analysis, 30 participants were eligible to be evaluated for level 3 outcomes of Kirkpatrick's Model (1994). This three-month analysis culminated in a 41\% response rate. Additionally, this sample included academic leaders with a range of experience, from novice leaders with less than two years of experience to seasoned leaders with more than ten years of experience. Another limitation is that analysis of level 4 outcomes did not align with the timeframe for reporting other levels of outcomes. 


\section{IMPLICATIONS}

Nursing and nursing education must transform to meet current and future health care needs. Well-equipped academic leaders are positioned to respond to calls for academic reform and transform the current academic landscape (Staffileno, Murphy, \& Carlson, 2016). However, structured leadership development is imperative for leaders to build and sustain intentional academic cultures and lead effective organizational change. Academic leadership immersion is essential in providing intensive knowledge-sharing and skill-building experiences to build leadership capacity. Implications for nursing education include strong support for leadership immersion to create sustainable change in nursing academia that is grounded in theory and data.

\section{NEXT STEPS}

Nursing programs are challenged to build and sustain quality academic cultures that well-prepare tomorrow's nurse to transform health care and meet the increasingly complex health care needs of the nation and beyond. In a context of rapidly evolving change, innovative leadership development is no longer optional if nursing education is to thrive and adapt in response to an ever-changing health care landscape.

\section{ACKNOWLEDGEMENTS}

We gratefully acknowledge the skill and talent of the Center for Faculty Excellence Instructional Designer, Stacie Sedlmayer, Web Development Manager, Nina Hutchinson, and Faculty Development Specialist, David Woodruff, who contributed to this project.

\section{AUTHOR BIOGRAPHIES}

Dr. Phillips is a Faculty Development Specialist for the Center for Faculty Excellence at Chamberlain College of Nursing. Dr. Phillips brings her expertise in experiential learning, innovative teaching strategies, new pedagogies, and the delivery of content using educational technology to support formation of excellent nurse educators. At Chamberlain and throughout the academic community, she is well regarded for her capacity to develop educators into engaged explorers of the teaching and learning process. Her many presentations and publications address the role of faculty development in transforming nurse educators and leading organizational change. In addition to her work in academia, Dr. Phillips has many years of experience as a board-certified nurse midwife.

Email: CPhillips2@Chamberlain.edu

Dr. Bassell graduated from Boston College with a BSN and Florida Atlantic University with an MSN. She earned a doctorate in education, in curriculum \& instruction with a focus on educational technology, from the University of Florida. She has over 15 years of academic experience across a variety of settings. She has participated in the development and implementation of imaginative and creative strategies to promote and support change in faculty's understanding of the teaching/learning process. She is currently a Faculty Development Specialist at Chamberlain College of Nursing. Email: KBassell@chamberlain.edu

Dr. Fillmore provides leadership for the Center of Faculty Excellence (CFE) She holds a Bachelor of Science in Nursing degree from Madonna University, a Master of Science in Nursing degree from the University of Phoenix, and a Doctor of Nursing Practice degree from Touro University. Over the course of her 30+ year career, she has held a broad range of roles in nursing practice, education, and educational leadership. Email: LFillmore@chamberlain.edu

Dr. Stephenson is a Faculty Development Specialist in the Center for Faculty Excellence at Chamberlain College of Nursing where she supports the development of nurse educators to achieve teaching excellence. She earned an RN degree from Pace University and an MSN and PhD from Georgia State University. Her career spans 22 years in academia, nursing administration, advanced nursing practice as a clinical nurse specialist, and medical/surgical nursing. Email: Wstephenson@chamberlain.edu 


\section{REFERENCES}

Benner, P., Sutphen, M., Leonard, V., \& Day, L. (2010) Educating nurses: A call for radical transformation. San Francisco, CA: Jossey-Bass.

Branson, C. M., Franken, M., \& Penney, D. (2016). Middle leadership in higher education: A relational analysis. Educational Management Administration \& Leadership, 44(1), 128-145.

Cannaby, A. M., Libacao, A., Hassanein, E., \& Gray, R. (2016). Do chief nurses need to be academically credible? Journal of Advanced Nursing. doi: 10.1111/jan.13139

Day, D. V., Fleenor, J. W., Atwater, L. E., Sturm, R. E., \& McKee, R. A. (2014). Advances in leader and leadership development: A review of 25 years of research and theory. The Leadership Quarterly, 25(1), 63-82.

Dreyer, A., Couper, I., Bailey, R., Talib, Z., Ross, H., \& Sagay, A. S. (2015). Identifying approaches and tools for evaluating community-based medical education programmes in Africa. African Journal of Health Professions Education, 7(1), 134-139.

Fritz, C. O., Morris, P. E., \& Richler, J. J. (2012). Effect size estimates: current use, calculations, and interpretation. Journal of Experimental Psychology: General, 141(1), 2.

Haji, F., Morin, M. P., \& Parker, K. (2013). Rethinking programme evaluation in health professions education: beyond 'did it work?'. Medical Education, 47(4), 342-351.

Halcomb, E., Jackson, D., Daly, J., Gray, J., Salamonson, Y., Andrew, S., \& Peters, K. (2015). Insights on leadership from early career nurse academics: findings from a mixed methods study. Journal of Nursing Management, 24, 155-163. doi: 10.1111 jonm. 12317

Halstead, J. (2009). Well-prepared faculty: Needed to achieve excellence in nursing education. In M. Adams \& T. Valiga (Eds). Achieving excellence in nursing education. (pp. 29-42). New York: National League for Nursing.

Kirkpatrick D. L. (1994). Evaluating training programs: The four levels. San Francisco, CA: Berrett-Koehler Publishers.

Lapkin, S., Levett-Jones, T., \& Gilligan, C. (2015). Using the Theory of Planned Behaviour to examine health professional students' behavioural intentions in relation to medication safety and collaborative practice. Nurse Education Today, 35(8), 935-940.

Leslie, K., Baker, L., Egan-Lee, E., Esdaile, M., \& Reeves, S. (2013). Advancing faculty development in medical education: a systematic review. Academic Medicine, 88(7), 1038-1045.

McPeck, J. E. (2016). Teaching critical thinking: Dialogue and dialectic. Routledge.

National Academies of Sciences, Engineering, and Medicine. (2015). Assessing progress on the Institute of Medicine Report. The Future of Nursing. Washington, DC: The National Academies Press.

Neal, E., \& Peed-Neal, I. (2010). Promoting your program and grounding it in the institution. In Gillespie, K. \& Robertson, D. (Eds). A guide to faculty development (99-115).

Opperman, C., Liebig, D., Bowling, J., Johnson, C. S., \& Harper, M. (2016). Measuring return on Investment for professional development activities: Implications for practice. Journal for Nurses in Professional Development, 32(4), 176-184.

Paradeise, C., \& Thoenig, J.C. (2013). Academic institutions in search of quality: Local orders and global standards. Organization Studies, 34(2), 189-218.

Rahmani, A., Mohammadi, A., \& Moradi, Y. (2016). Effectiveness of scenario-based education on the performance of the nurses in the critical cardiac care unit for patients with acute coronary syndrome. Health Sciences, 5(8), 218-224.

Sarikaya, O., Kalaca, S., Yegen B. C., \& Cali, S. (2010). The impact of a faculty development program: evaluation based on the self-assessment of medical educators from preclinical and clinical disciplines. Advances in Physiology Education, 34(2), 35-40. doi: 10.1152/advan.00024.2010

Sabelli, N., \& Dede, C. (2013). Empowering design based implementation research: The need for infrastructure. Design-based implementation research: Theories, methods, and exemplars. National Society for the Study of Education Yearbook, 112(2), 464-480.

Santalucia, S., \& Johnson, C. R. (2010). Transformative learning: Facilitating growth and change through fieldwork. OT Practice, 15(19), CE1-CE7.

Sherwood, G., \& Horton-Deutsch, S. (2014). Reflective organizations: On the front lines of QSEN \& reflective practice implementation. Indianapolis: Sigma Theta Tau Press.

Söderhjelm, T., Björklund, C., Sandahl, C., \& Bolander-Laksov, K. (2016). Academic leadership: management of groups or leadership of teams? A multiple-case study on designing and implementing a team-based development programme for academic leadership. Studies in Higher Education, 1-16.

Staffileno, B. A., Murphy, M. P., \& Carlson, E. (2016). Overcoming the tension: Building effective DNP-PhD faculty teams. Journal of Professional Nursing, 32(5), 342-348. doi: http://dx.doi.org/10.1016/j.profnurs.2016.01.012

Steinert, Y. (2014). Faculty Development: Future Directions. In Faculty Development In The Health Professions (pp. 421-442). Springer Netherlands.

Zheng, M., Bender, D., \& Nadershahi, N. (2015). Faculty professional development in emergent pedagogies for instructional innovation in dental education. European Journal of Dental Education. 